\title{
Educação pública como direito social: desafios para a construção de um sistema articulado no Brasil
}

\author{
Benedito de Jesus Pinheiro Ferreira ${ }^{1}$ \\ http://orcid.org/0000-0003-1949-5077 \\ ${ }^{1}$ Universidade Federal do Pará, Programa de Pós-Graduação em Educação, Belém, PA, Brasil.
}

Educação pública como direito social: desafios para a construção de um sistema articulado no Brasil Resumo: Este artigo analisa, por meio de revisão de literatura, referenciada teoricamente na pedagogia histórico-crítica, determinações fundamentais da educação pública no Brasil, buscando compreender os desafios colocados para a efetivação de uma práxis educativa radicalmente voltada à emancipação humana. São tratadas três questões intimamente relacionadas: a difículdade histórica de constituição de um sistema nacional de educação; os crônicos problemas de subfinanciamento estatal, como elemento-chave das políticas educacionais, especialmente nas últimas décadas; e a hegemonia de pedagogias do aprender a aprender, que renovam o discurso desqualificador da atividade de transmissão do conhecimento humano historicamente produzido em suas formas mais desenvolvidas. Conclui-se apontando a necessidade da defesa da educação pública como um direito social, articulado às lutas por um projeto educacional emancipatório, que precisam estar baseadas na produção de conhecimento sobre a realidade educacional brasileira, a partir de um referencial teórico que dê conta de apreender o caráter contraditório dessa realidade, que constitui uma particularidade do capitalismo periférico.

Palavras-chave: Educação contra-hegemônica. Sistema nacional. Financiamento educacional. Teorias pedagógicas.

Public Education as a Social Right: challenges for the construction of a coordinated system in Brazil Abstract: This study aimed to understand the challenges arising from the implementation of an educational praxis radically focused on human emancipation. Through a literature review, theoretically referenced in historical-critical pedagogy, the research analyzed fundamental determinations of public education in Brazil. Three closely related issues were addressed: the historical difficulty of establishing a national education system; the chronic problems of funding as a key element of educational policies, especially in recent decades; and the hegemony of learning-to-learn pedagogy, which open space for a discourse that harms the activity of transmission of historically produced human knowledge in its most advanced forms. The results point to the need to protect public education as a social right, linked to the struggles for an emancipatory educational project. This project needs to be supported by the production of knowledge about the Brazilian educational reality, based on a theoretical framework that can capture its contradictory nature, which constitutes a particularity of peripheral capitalism.

Keywords: Counter-hegemonic education. National system. Educational funding. Pedagogical theories.

Recebido em 01.02.2019. Aprovado em 16.04.2019. Revisado em 19.07.2019.

\section{(@) $\mathbb{Q} \otimes$}

(C) O(s) Autor(es). 2019 Acesso Aberto Esta obra está licenciada sob os termos da Licença Creative Commons Atribuição-NãoComercial 4.0 Internacional (https://creativecommons.org/licenses/by-nc/4.0/deed.pt_BR), que permite copiar, distribuir e reproduzir em qualquer meio, bem como adaptar, transformar e criar a partir deste material, desde que para fins não comerciais e que você forneça o devido crédito aos autores e a fonte, insira um link para a Licença Creative Commons e indique se mudanças foram feitas. 


\section{Introdução}

Parte-se do pressuposto de que a formulação mais radical, no sentido histórico/ontológico, do fenômeno educativo é aquela que o vincula diretamente ao processo mesmo de humanização (SAVIANI, 2005). Isto porque um indivíduo nasce já pertencente à espécie humana, mas o seu pertencimento ao gênero humano se dá, gradativamente, na medida da apropriação da cultura humana historicamente desenvolvida, sendo a linguagem (falada e posteriormente escrita) um dos mais importantes elementos-chave, condição para um pensamento elaborado, portanto do desenvolvimento especificamente humano da consciência. Efetivamente, é esta dinâmica que mais propriamente diferencia o ser humano das demais espécies. Nesse sentido, a ação educativa é sempre baseada em uma dialética humanização/alienação, por incidir em uma contínua, porém sempre limitada, apropriação das objetivações humanas (DUARTE, 2013), processo indispensável para que o indivíduo possa agir de forma humana, incluindo-se o desenvolvimento da possibilidade de criação de novas objetivações a serem legadas ao coletivo social presente e futuro.

Outro importante pressuposto teórico deste estudo é a adoção da categoria trabalho como princípio educativo, "[...] já que a ordem social e estatal (direitos e deveres) é introduzida e identificada na ordem natural pelo trabalho", dessa forma confrontando-se com as concepções mágicas de mundo e fornecendo "[...] o ponto de partida para o posterior desenvolvimento de uma concepção histórico-dialética do mundo [...]". (GRAMSCI, 1995, p. 130). Nas primeiras formas históricas, a educação efetivamente coincidia com o processo do trabalho: no trabalho, diretamente, as novas gerações, pela mediação de outros indivíduos (tipicamente pertencentes à geração anterior) se apropriavam de instrumentos, formas de cooperação, e técnicas indispensáveis. Com o advento das sociedades de classes, ocorre a cisão entre duas formas de educação: uma destinada às classes dominantes, que se dava em um espaço específico (a escola, ou o espaço do ócio); outra, para as classes subalternas, na qual a educação continuava ocorrendo de forma concomitante ao trabalho. Uma mudança substantiva ocorrerá com o advento da sociedade burguesa, na qual a classe dominante tinha o interesse num maior grau de generalização da educação formal, visando preparar trabalhadores para as suas funções na produção capitalista. Efetivamente, tomar o trabalho como categoria central para a compreensão do fenômeno educativo é condição para se estar de acordo com os princípios do materialismo histórico, segundo o qual "[...] a produção, e junto com ela também a troca de seus produtos, é o fundamento de toda ordem social [...]”. (ENGELS, 2015, p. 304).

Como consequência dos princípios acima enunciados, cabe explicitar que o campo educacional é profundamente marcado por antagonismos de classes, que assumem características próprias, que precisam ser desveladas no atual período histórico e na particularidade de uma sociedade periférica do capitalismo, que é a sociedade brasileira. Trata-se de contexto profundamente marcado por uma aguda crise do capital, em que "[...] a alienação do trabalho vem se intensificando e aprofundando com as transformações tecnológicas, a supressão do poder organizado dos movimentos da classe trabalhadora [...]" (HARVEY, 2018, p. 193), crise que se expressa não só no nível econômico, com o desemprego, subemprego e perda de sentido do trabalho, mas no campo ético, ambiental, em suma, afetando todo o modelo civilizatório vigente, que assume como traço essencial uma constante degradação da vida da maioria da população, retirada de direitos, e a própria contestação de valores em torno de bens públicos, e a correlata afirmação do individualismo como orientação suprema, inclusive na competição desenfreada pelas oportunidades de trabalho, o que corrompe a necessária solidariedade entre os indivíduos da classe trabalhadora.

Para discutir a natureza desses impasses e antagonismos e as possibilidades da educação como um direito social e um bem público efetivamente articulado à emancipação humana, este artigo abordará, tendo como referência teórica a pedagogia histórico-crítica (SAVIANI, 2005), três questões-chave e seus desafios correspondentes: a necessidade de um sistema nacional articulado de educação (SAVIANI, 2017); o debate histórico relativo às concepções pedagógicas; e a questão do financiamento público da educação. São três tópicos profundamente interligados, separados apenas para fins expositivos nas três seções seguintes, compondo a estrutura do presente texto. Na sequência serão feitas as considerações finais.

\section{$O$ (inexistente) sistema articulado de educação no País}

A importância de um sistema educacional articulado é de tal monta que Saviani (2008b, p. 214) chega a afirmar que o tema constitui "[...] a maior criação da educação ocidental nos séculos XIX e XX". Cabe, contudo, para se apreender a importância, resgatar em que consiste um sistema educacional para além dos reducionismos comuns em torno da terminologia relativa ao tema, e em especial caracterizar os diversos obstáculos históricos para a sua constituição no Brasil. Primeiramente, verifica-se o uso banalizado do termo 
sistema, no sentido geral e impreciso de elementos articulados, cabendo, portanto, falar-se de sistema públi$\mathrm{co/sistema} \mathrm{privado,} \mathrm{sistemas} \mathrm{federais,} \mathrm{estaduais} \mathrm{etc.} \mathrm{Esse} \mathrm{tratamento} \mathrm{impreciso} \mathrm{(sentido} \mathrm{não} \mathrm{explicitado)} \mathrm{aca-}$ ba por obscurecer a apreensão da questão, e, portanto, da gravidade da persistência histórica da não constituição de um sistema educacional no País, e da necessidade de se lutar pela reversão dessa realidade. Um exemplo flagrante dessa imprecisão é o fato de a legislação educacional referir-se a um sistema municipal de ensino, quando essa própria legislação impede a sua existência. É imperiosa, portanto, a explicitação do sentido preciso. Para além da ideia de redes de escolas:

[...] o termo sistema denota um conjunto de atividades que se cumprem tendo em vista determinada finalidade. E isso implica que as referidas atividades são organizadas segundo normas decorrentes dos valores que estão na base da finalidade preconizada. Assim, sistema implica organização sob normas próprias (o que lhe confere um elevado grau de autonomia) e comuns (isto é, que obrigam a todos os seus integrantes). (SAVIANI, 2008b, p. 215).

Cumpre destacar a centralidade da questão da autonomia, incidente nessa discussão, e isto em dois sentidos complementares: é crucial um importante grau de autonomia de um sistema educacional, baseado em normas bem estabelecidas, para que o mesmo não seja vulnerável a flutuações das orientações de política (comuns no caso brasileiro, como se discutirá adiante). O outro sentido importante de autonomia se refere às partes do sistema; caso típico, a autonomia dos subsistemas estaduais frente às determinações de âmbito federal. Aqui cabe um equilíbrio: nem uma hierarquia rígida, nem um descolamento absoluto das partes com o todo. Nas palavras de Saviani (2008b, p. 13), “[...] sistema não é unidade da identidade, uma unidade monolítica, indiferenciada, mas unidade da diversidade, um todo que articula uma variedade de elementos que, ao se integrarem ao todo, nem por isso perdem a própria identidade".

Outra consequência dessa concepção de sistema educacional é a de que "[...] só se pode falar em sistema, em sentido próprio, na esfera pública" (SAVIANI, 2008b, p. 215), haja vista a exclusividade do Estado na legitimidade em determinar normas a serem seguidas por toda a coletividade, legitimidade esta tanto mais reforçada, no que diz respeito ao tema em discussão, na medida da compreensão da educação como algo de interesse público, noção própria da modernidade.

Um dos mais expressivos sintomas da não efetivação de um sistema articulado de educação no Brasil é a persistência histórica da não realização de uma meta reiteradamente anunciada pelo poder público, e das mais fundamentais para um projeto educativo: a erradicação do analfabetismo e universalização da educação fundamental ou primária. Mesmo se confrontados com indicadores de países vizinhos, os dados de 2000 sobre analfabetismo (população acima de 15 anos) são bastante graves. Conforme dados do Instituto Nacional de Estudos e Pesquisas Educacionais Anísio Teixeira (INEP) ([200-]), enquanto Argentina e Chile apresentam 3,2\% e 4,2\%, respectivamente, de população analfabeta (de 15 anos ou mais), o Brasil amarga a cifra de 13,6\% de analfabetos (mais de 16 milhões de pessoas), situando-se mesmo na retaguarda de países que tem Índice de Desenvolvimento Humano (IDH) muito próximo, como é o caso de Colômbia e Equador, ambos com 8,4\% no mesmo indicador ${ }^{1}$.

A série histórica revela que o Brasil passou de $65,3 \%$ de analfabetos em 1900 para os citados 13,6\% de 2000. Contudo, o que parece revelar uma significativa melhoria, efetivamente esconde uma notável ampliação dos números absolutos, de 6,3 milhões para 16,3 milhões nesse período (INSTITUTO NACIONAL DE ESTUDOS E PESQUISAS EDUCACIONAIS ANÍSIO TEIXEIRA, [200-]) o que mais se agrava se se considera o fato à luz dos notáveis avanços científicos, tecnológicos e de gestão ocorridos no decorrer de um século. Cabe mencionar dados comparativos semelhantes, do final do século XIX, que mostram as raízes históricas do atraso no campo educacional: em 1898, a Argentina tinha apenas 6\% da sua população escolarizada; esse percentual, contudo, para o Brasil situava-se em ínfimos 1,8\%. (ALMEIDA, 1989).

Esses dados evidenciam uma histórica ausência de políticas consistentes no campo educacional. E um dos aspectos fundamentais dessa realidade é a profunda descontinuidade das políticas educacionais, que, segundo Saviani (2008b, p. 221), “[...] descrevem um movimento que pode ser reconhecido pelas metáforas do ziguezague ou do pêndulo". O autor cita uma longa cadeia de reformas educacionais no Brasil, destacando:

[...] a tendência em nomear as reformas pelos seus proponentes, em geral ministros da pasta de instrução pública ou da educação, a indicar que quem chega ao poder procura imprimir sua marca, desfazendo o que estava em curso e projetando a ideia de que com ele, finalmente, o problema será resolvido. (SAVIANI, 2008b, p. 221).

Um dos aspectos relativos ao tema da organização da educação nacional e que se inscreve no citado movimento pendular diz respeito à questão centralização/descentralização, seja em termos de políticas de 
colaboração entre entes federativos, prerrogativas para definir normas (ocorrendo inconsistências na própria Constituição $\mathrm{Federal}^{2}$ ), atribuições de papeis e responsabilidades (ou, antes, desresponsabilização). Tais oscilações, características de um movimento de forte descontinuidade nas políticas educacionais, chegam a produzir uma situação paradoxal: a Lei n ${ }^{\circ}$ 13.005/2014 (BRASIL, [2014]), que institui o Plano Nacional de Educação (PNE), estabelece, na sua Meta 20, a obrigação do poder público em atribuir até 2024 recursos pelo menos da ordem de $10 \%$ do Produto Interno Bruto/PIB, o que resulta em letra morta pela não definição clara das responsabilidades dos entes públicos em relação a esta determinação.

Em suma, a não existência de um sistema articulado de educação no Brasil liga-se a questões de ordem política, ideológica, legal, porém, uma questão-chave ou articuladora das demais é a do crônico subfinanciamento da área, tratado a seguir.

\section{O subfinanciamento histórico: peça-chave da política educacional brasileira}

A inexistência de um sistema articulado de educação nacional, conforme acima discutido, inviabiliza o estabelecimento de fins claros a serem atingidos, e dos meios indispensáveis a esses fins, predominando a descontinuidade das políticas educacionais. Precisamente essa inexistência se reflete, em termos de financiamento, tanto na crônica insuficiência de recursos, quanto na sucessiva adoção de políticas que são incapazes tanto de efetivar fins mais amplos quanto garantir, no bojo dessas políticas, homogeneidade de atendimento no território nacional.

Na legislação brasileira, historicamente, foram estipulados, inclusive no nível constitucional, parâmetros mínimos de financiamento da educação. Some-se a isso, um conjunto de políticas de fundos (tais como o Fundo de Manutenção e Desenvolvimento do Ensino Fundamental e de Valorização do Magistério/FUNDEF e o Fundo de Manutenção e Desenvolvimento da Educação Básica/FUNDEB), o que aparentemente daria consequência a tão disseminada proclamação de prioridade à educação. Contudo, diversos obstáculos se interpõem à essa concretização, seja na retirada da efetividade desses mecanismos legais, seja no próprio descumprimento dos mesmos.

O primeiro importante mecanismo de comprometimento dos recursos à área educacional aplica-se diretamente à Constituição Federal de 1988 (BRASIL, [2019]), que estabelece em seu artigo 212, a aplicação de no mínimo $18 \%$ da receita de impostos da União na manutenção e desenvolvimento do ensino (25\% para os estados, distrito Federal e municípios). A burla a esta vinculação de verbas começou a se dar na priorização de estabelecimento, no campo tributário, de contribuições (no lugar de impostos) ${ }^{3}$. Somando-se a isso, é estabelecido um mecanismo de Desvinculação das Receitas da União (DRU), desvinculando 20\% das receitas gerais, o que incidindo nos citados $18 \%$, reduzia-os a $14,4 \% 4$.

Note-se que o estabelecimento de uma vinculação constitucional funciona como um importante fundo mínimo de recursos visando fazer frente aos desafios educacionais do País (sem que haja a denominação de fundo e sem os efeitos propagandísticos correlatos). Paradoxalmente - tendo-se em vista a adoção dos já citados impedimentos à efetivação desse fundo de longo prazo (dada sua natureza constitucional) e com recursos voltados à educação na sua totalidade - é estabelecida em âmbito federal, conforme citado anteriormente, uma política de fundos de desenvolvimento do ensino e do magistério, temporários e voltados a segmentos específicos da educação. Inicialmente, o FUNDEF (regulamentado pela Lei n 9.424/1996) e, posteriormente, o FUNDEB (Lei n $\left.{ }^{0} 11.994 / 2007\right)$.

O FUNDEF, com prioridade explicitada ao ensino fundamental, como prescrevem os organismos internacionais (HADDAD et al., 2008), praticamente, apesar do que sugere sua denominação, não se traduziu em recursos novos para a educação, pois, de acordo com Davies (2006, p. 756), “[...] apenas redistribuiu, em âmbito estadual, entre o governo estadual e os municipais, uma parte dos impostos que já eram vinculados à MDE [manutenção e desenvolvimento do ensino] antes da criação do Fundo [...]". De fato, apesar de ser uma política de iniciativa do governo federal, a sua complementação, além de ser irrisória, foi sistematicamente burlada.

Davies (2006) afirma que a União deixou de aplicar mais de R\$ 12,7 bilhões de 1998 a 2002, reconhecidos pelo próprio MEC, e faz uma projeção de aproximadamente R\$ 30 bilhões até 2006 da dívida dos governos de Fernando Henrique Cardoso e Luiz Inácio Lula da Silva, pelo descumprimento da determinação legal do FUNDEF. Vale mencionar ainda que, como se trata de política baseada numa lógica de redistribuição, embora tenha havido municípios que tiveram seus recursos para a educação aumentados, igualmente houve um número significativo de municípios que perderam recursos.

Quanto ao FUNDEB, criado com a pretensão de correção de problemas do FUNDEF, (este deixava de fora a educação infantil, Educação de Jovens e Adultos/EJA, ensino médio, e seus profissionais), para além da questão da complementação igualmente irrisória de recursos, cabe citar a fala do estudioso do tema financia- 
mento da educação, Nicholas Davies, que se refere não só à questão de recursos, mas à fragilidade da própria concepção dessa política de fundos, o que reforça a inconsistência decorrente da inexistência de um sistema articulado de educação, conforme discutido na seção anterior. Para Davies (2006, p. 755):

No caso dos fundos formais, um grande risco é de eles agravarem a fragmentação da educação escolar, ao privilegiarem um nível de ensino (o ensino fundamental regular, no caso do FUNDEF). Ora, a educação não pode ser pensada em pedaços, como se uma parte (a graduação ou a pós-graduação, por exemplo) pudesse funcionar bem sem as outras (a educação básica, por exemplo). Só uma perspectiva de totalidade, abrangendo desde a creche até a pós-graduação, pode enfrentar alguns dos problemas básicos da educação.

Em um recente balanço de 30 anos de mobilização social em torno dos recursos constitucionais para a educação, Pinto (2018) refere-se à complementação da União ao FUNDEB, de $0,2 \%$ do PIB, bastante aquém do necessário para a equalização das oportunidades educacionais no país. $\mathrm{O}$ autor, à guisa de balanço desse fundo, afirma ser necessário reconhecer seu papel na equalização de gastos por aluno, mas entende como "[...] evidentes os limites desse processo, caso se mantenha o desenho atual desse fundo". (PINTO, 2018, p. 865).

Retomando-se a questão da vinculação constitucional de (no mínimo) $18 \%$ de recursos de impostos da União ao campo educacional, poderia ser auspicioso o fato de que, após inúmeros estudos e décadas de mobilização social denunciando os mecanismos espúrios de burla à vinculação, seria estabelecida, via $\mathrm{EC}{ }^{\circ} 59$ / 2009 (BRASIL, [2009a]) a progressiva eliminação da incidência da DRU sobre a educação: redução de $20 \%$ para 12,5\%, em 2009; 5\%, em 2010; e extinção em 2011. Cabe acrescentar também como um alento aos que lutam pela educação pública, a aprovação do Plano Nacional de Educação (Lei no 13.005, de 24 de junho de 2014) (BRASIL, [2014]), estabelecendo importantes metas referidas desde a educação básica à educação superior (graduação e pós-graduação), que demandam substancial elevação de recursos para a educação brasileira. O PNE 2014-2024, nesse sentido, determina, em sua meta 20, a elevação, até 2024, dos recursos públicos para a educação brasileira, à ordem equivalente a $10 \%$ do PIB, “[...] o que significa quase que dobrar o volume de recursos financeiros". (AMARAL, 2017, p. 7).

Contudo, a esse suposto alento trazido pelo restabelecimento da vinculação dos $18 \%$ viria se sobrepor o advento do novo regime fiscal. Efetivamente, a partir de 2018 essa vinculação:

[...] deixa de existir, ao menos para a União, nos termos do art. 110, inciso II, da EC n ${ }^{\circ} 95 / 2016$, que estabelece que os gastos com educação devem se sujeitar ao novo regime fiscal, que determina o congelamento das despesas primárias por vinte exercícios financeiros, admitindo-se apenas a correção do total da despesa pelo Índice de Preços ao Consumidor Amplo (IPCA), tomando como referência o exercício financeiro de 2017. (PINTO, 2018, p. 861).

Em suma, o que ocorre no conjunto da política nacional de financiamento educacional pode ser expresso frequentemente pelo adágio dar com uma mão e tirar com a outra. Pode-se citar, nesse sentido, o estabelecimento, já na lei de Diretrizes e Bases da Educação/LDB (Lei no 9.394/1996), da exigência de estatutos e planos de carreira, com progressão funcional; ingresso na carreira exclusivamente por concurso público de provas e títulos; piso salarial; carga horária de trabalho que incluísse período para estudos, planejamento e avaliação. Adicionalmente, a já citada lei que regulamentou o FUNDEF, do mesmo ano que a LDB, determinou o prazo de seis meses, a partir da sua vigência, para a elaboração dos planos de carreira por parte de estados, municípios e Distrito Federal, "[...] prazo [que] foi descumprido por todos os entes federados". (JACOMINI; PENNA, 2016, p. 179). Também desde o Plano Nacional de Educação 2001/2011, Lei no 10.172/2001, (BRASIL, [2009b]), estabelecia-se "[...] jornada de trabalho de tempo integral, quando conveniente, cumprida em um único estabelecimento escolar". (BRASIL, [2009b], grifo nosso). Vale destacar a expressão quando conveniente que confere à questão o mero caráter de recomendação. Isto é, muitas vezes após décadas de luta dos movimentos ligados à educação, alcança-se a consignação legal de um conjunto de demandas históricas desses movimentos que encontram, entretanto, inúmeras barreiras para a sua efetivação, seja pelo descumprimento por parte do poder público, seja por conta de um outro mecanismo legal que advém para tornar letra morta o anterior.

A questão do financiamento da educação, não obstante as declarações de boa intenção dos governos - e mesmo da materialização de importantes princípios em uma legislação, com forte grau de fragmentação - efetivamente, não se separa (ou, antes, é completamente dependente) da concepção geral acerca da destinação do fundo público, submetida ao jogo de poder dos grupos hegemônicos. E a prioridade maior nos sucessivos governos tem sido "[...] o pagamento dos juros e amortizações da dívida pública em detrimento do financiamento das áreas sociais, entre elas a educação". (LIMA, 2012, p. 627). Atualmente, o efeito dessa priorização assume proporções 
muito mais graves com o já referido novo regime fiscal, materializado, apesar de fortes embates na sociedade, pela Emenda Constitucional 95/2016 (BRASIL, [2016]), dado que o congelamento, por 20 anos, das despesas primárias afeta todo o conjunto de políticas sociais, e "[...] além de decretar a "morte" do PNE (2014-2024), promoverá maior desigualdade social, maior concentração de renda [...]". (AMARAL, 2016, p. 671).

Vale destacar que o PNE 2014-2024 já era suscetível de críticas em muitos aspectos: por apontar, como de costume nos planos governamentais, a efetivação de recursos na ordem de $10 \%$ do PIB nacional no horizonte de uma década, além de não estabelecer claramente qual a instância governamental que seria cobrada pelo cumprimento de tal determinação; pelas inúmeras aberturas para aplicação de recursos públicos na forma de subsídios ao setor privado da educação, incluindo-se os cursos na modalidade a distância, dentre outros aspectos. Com efeito, a partir de um estudo minucioso da Lei ${ }^{\circ}$ 13.005/14 (BRASIL, [2014]), que institui o último PNE, $\operatorname{Lima}(2015$, p. 40) afirma que "[...] foi aprovada mais uma expressão da fundamentação política e jurídica para aprofundamento da privatização da educação brasileira".

Ao se fazer, portanto, referência à morte do PNE, não se está lamentando a perda da materialização dos caros princípios sustentados pelas entidades que historicamente vêm lutando pela educação pública, gratuita, laica e referenciada nos interesses do conjunto da sociedade brasileira. Mas trata-se de afirmar que muito se agravou uma situação que em si já demandava a continuidade de uma acirrada luta na disputa por projetos antagônicos no campo educacional. Para se ter uma ideia desse agravamento das perdas orçamentárias, vale citar um estudo de Amaral (2016) que procura estimar o que ocorreria se os recursos de Manutenção e Desenvolvimento da Educação (MDE) e os das Universidades Federais estivessem submetidos desde a década de 1990 às regras estabelecidas no novo regime fiscal. Como se trata de estudo referente a um período passado, algumas hipóteses têm que ser formuladas (acerca, por exemplo, do cumprimento ou não da vinculação constitucional de 18\%), mas seus cálculos comparativos chegam a indicar uma situação em que "[...] teríamos um total acumulado de $\mathrm{R} \$ 378,7$ bilhões, que seriam subtraídos da educação no período 1998-2016" (AMARAL, 2016, p. 664), algo em torno da importante cifra de R $\$ 20$ bilhões por ano. Em suma, o autor conclui que o regime fiscal estabelecido na EC-95 (Emenda Constitucional n. 95) "[...] impossibilita o cumprimento das metas do PNE (2014-2024), exatamente como ocorreu com o PNE (2001-2011) [...]". (AMARAL, 2016, p. 662).

Cabe registrar que no caso do PNE 2001-2011, nove metas que garantiriam o aporte de recursos para que o conjunto do plano se viabilizasse (deixando de ser assim apenas uma carta de intenções), foram vetadas pelo Executivo, no governo de Fernando Henrique Cardoso, não ocorrendo igualmente nos dois mandatos de Luiz Inácio Lula da Silva uma mobilização da base parlamentar governista para a derrubada desses vetos. Isto é, o padrão de secundarização crônica das áreas sociais, dentre elas a educação, se verifica, por vias distintas, mas em geral em nome do imperioso equilíbrio fiscal, sem o qual o País entraria em colapso, segundo o discurso hegemônico.

\section{A disputa em torno das teorias pedagógicas}

O campo pedagógico, como conjunto de princípios teóricos articulados, com fim e meios próprios, constituise com o advento da sociedade moderna, e da necessidade, para a consolidação dessa sociedade, de uma mudança da concepção de mundo própria do período feudal, baseada em relações hierárquicas (tanto a relativa a divindades e seres humanos, como nas relações de trabalho baseadas na servidão), para uma concepção moderna, baseada agora na relação entre cidadãos formalmente livres, e no trabalho assalariado. Tal mudança de concepção e as mudanças nas relações de produção que lhes servem de base colocavam na ordem do dia a universalização das capacidades básicas de leitura e escrita, juntamente com rudimentos da matemática e das várias ciências. A educação gradativamente passa do âmbito privado (atividade conduzida por preceptores) para um espaço público, a escola, com a correspondente exigência de uma atividade crescentemente sistematizada.

Constitui-se, portanto, a que virá posteriormente a ser denominada pedagogia tradicional, referida predominantemente, ao longo do Século XX do ponto de vista da crítica que é inaugurada pelo movimento escolanovista. De fato, àquela pedagogia marcadamente mecânica, ao caráter formalista e estático dos conhecimentos transmitidos, à excessiva ênfase na memorização, à unilateralidade na relação professor-aluno etc., caberia sim realizar uma crítica contundente, apontando sua renovação. Ocorre que o movimento da pedagogia nova, deixando de atentar para o movimento dialético da história, onde as superações sempre comportam certo grau de incorporação de elementos válidos, advoga uma atitude de superação por eliminação, uma ruptura absoluta, que se manifesta em várias dimensões: secundarização ou mesmo negação da importância da transmissão de conhecimentos (e, portanto o ensino) para colocar em primeiro plano a aprendizagem realizada autonomamente pelo aluno, que deveria ocupar o centro do processo; o deslocamento do plano lógico-filosófico, para o psicológico; da disciplina para a atividade espontânea do aluno. Antonio Gramsci, já na 
década de 1930, referindo-se ao movimento pedagógico renovador na Itália, caracteriza lapidarmente a natureza da crítica então empreendida, afirmando que:

Ainda se está na fase romântica da escola ativa, na qual os elementos da luta contra a escola mecânica e jesuítica se dilataram morbidamente por causa do contraste e da polêmica: é necessário entrar na fase 'clássica', racional, encontrando nos fins a atingir a fonte natural para elaborar os métodos e as formas. (GRAMSCI, 1995, p. 124, grifo nosso).

Para a superação dessa fase romântica, cabe, inicialmente, compreender a natureza das teorias pedagógicas hegemônicas (tanto no ideário pedagógico, quanto das políticas oficiais), como pressuposto para a construção de uma teoria pedagógica efetivamente revolucionária. Saviani (2008a) chama a atenção para o fato de que tanto a pedagogia tradicional quanto a pedagogia nova, apesar de esta última assumir um discurso eminentemente renovador, configuram-se teorias que se situam na perspectiva liberal de educação, e a ambas falta a perspectiva historicizadora, na medida em que não assumem o caráter determinado da educação. De fato, a pedagogia nova é caracterizada pelo autor como um primeiro mecanismo de recomposição de hegemonia burguesa, uma vez que no momento em que se intensificam as pressões pela igualdade de acesso à escola e, portanto, aos conteúdos ali veiculados, o espírito renovador, ao secundarizar a transmissão de conteúdos, em favor do aprender a aprender, "[...] subordinou as aspirações populares aos interesses burgueses tornando possível à classe dominante apresentar-se como a principal interessada na reforma da escola [...]" (SAVIANI, 2008a, p. 52). O estudo histórico das ideias pedagógicas mostra que, apesar da elaboração de propostas contra-hegemônicas, surgem, de forma cíclica, outros momentos de recomposição de hegemonia burguesa, sempre se apresentando como uma ruptura radical em relação àquilo que denominam como tradicional. Tal ocorre, nos anos 1970, com o advento da pedagogia tecnicista, bastante afinada com a teoria do capital humano, e de um conjunto de propostas que formarão um verdadeiro amálgama a partir dos anos 1990, que Saviani denominará conjuntamente de neoprodutivismo, com suas variantes: neo-escolanovismo, neoconstrutivismo, neotecnicismo (SAVIANI, 2013).

Esse mesmo autor formula a necessidade de síntese entre os elementos da escola tradicional e os da escola nova de acordo com os seguintes princípios: No plano filosófico histórico, caberia reconhecer que tanto a pedagogia tradicional quanto a pedagogia nova realizavam uma inversão idealista ao conceberem a escola como um elemento capaz de, por si mesma, transformar a sociedade, resolvendo a questão do acesso desigual às oportunidades. Cabe, dialeticamente, conceber a educação como elemento condicionado, porém capaz de conter espaços de contradição, isto é, capaz de influenciar o elemento determinante, já que "Ainda que secundário, nem por isso deixa de ser instrumento importante e por vezes decisivo no processo de transformação da sociedade". (SAVIANI, 2008a, p. 53). E essa transformação, no sentido de promoção de uma igualdade real (não só formal), "[...] está associada à transformação dos conteúdos formais, fixos e abstratos, em conteúdos reais, dinâmicos e concretos". (SAVIANI, 2008a, p. 52).

No plano pedagógico-metodológico, trata-se de estabelecer as condições que sejam capazes de servir de mediação dos alunos com o acervo de conhecimento historicamente produzido. Nas palavras de Saviani (2008a, p. 56):

Serão métodos que estimularão a atividade e iniciativa dos alunos sem abrir mão, porém, da iniciativa do professor; favorecerão o diálogo dos alunos entre si e com o professor, mas sem deixar de valorizar o diálogo com a cultura acumulada historicamente; levarão em conta os interesses dos alunos, os ritmos de aprendizagem e o desenvolvimento psicológico, mas sem perder de vista a sistematização lógica dos conhecimentos, sua ordenação e gradação para efeitos do processo de transmissão-assimilação dos conteúdos cognitivos.

Finalmente, no plano especificamente político, coloca-se no centro a questão da democracia, e sobre esta cabe destacar que, sendo a educação uma atividade mediadora (não possui um fim em si mesma), a democracia buscada nesse campo é aquela referida à sociedade, na forma da apropriação dos elementos culturais humanos de forma igualitária, e não somente a democratização das relações internas à escola, que muitas das vezes se converteram em uma pseudodemocracia. Segundo o alerta de Saviani:

[...] se a democracia supõe condições de igualdade entre os diferentes agentes sociais, como a prática pedagógica pode ser democrática já no ponto de partida? [...] agir como se as condições de igualdade estivessem instauradas desde o início não significa, então, assumir uma atitude de fato pseudodemocrática? (SAVIANI, 2008a, p. 62). 
Duarte (2010) aponta igualmente a necessidade de uma disputa, no campo teórico, no sentido da superação da atual hegemonia das pedagogias do aprender a aprender, que têm o traço fundamental de secundarizar a transmissão de conhecimentos sistematizados e sustentarem-se no relativismo, tanto cultural quanto epistemológico: construtivismo, teoria do professor reflexivo, pedagogia das competências, pedagogia dos projetos, e pedagogia multiculturalista.

\section{Considerações finais}

Este artigo estabeleceu como objetivo enfocar, dentre as determinações fundamentais da educação pública brasileira, três temas profundamente relacionados, entendidos como chaves de compreensão dos impasses para a efetivação da educação como um direito social no País. Parte-se do pressuposto de que continuam sendo fundamentais as lutas coletivas da sociedade brasileira pela educação pública, gratuita, laica e de qualidade referenciada nas necessidades da maioria da população brasileira, e de que essas lutas serão tanto mais eficazes quanto maior for a capacidade de se elaborar uma acurada compreensão dessa realidade a ser modificada, e de que tal compreensão pode ser enriquecida tendo-se por base o materialismo histórico dialético, pela orientação de seu método de, partindo-se da aparência, buscar, via abstração (análise) e posterior esforço de síntese, elaborar-se a apreensão concreta dessa realidade, com as contradições próprias de uma particularidade do capitalismo periférico/dependente, como o Brasil.

Dentre essas contradições, cabe destacar a necessidade das frações de classe hegemônicas de, no plano material, garantir-se uma educação à população, minimamente adequada às necessidades do trabalho submetido ao capital; e, no plano ideológico, ceder parcialmente às pressões dos movimentos sociais - ou até mesmo se apropriar de determinadas bandeiras de luta desses movimento - como elemento importante para manutenção de sua hegemonia; porém seus interesses imediatos, de maximização de lucro lastreada no fundo público, os impulsionam a criar mecanismos que, em forte medida, inviabilizam a materialização dos avanços dos direitos sociais. Como exemplo marcante, o ambicioso conjunto de metas estabelecidas no PNE 20142024, entrando em contradição com seu caráter privatista, e posteriormente com a sua própria inviabilização por conta do estabelecimento de um regime fiscal (EC-95) voltado a garantir os ganhos desses setores hegemônicos. Cabe destacar um outro elemento contraditório, aparentemente ignorado pela perspectiva imediatista orientada para ganhos de curto prazo: o novo regime fiscal, associado a uma forte retirada de direitos no campo trabalhista, e consequente brutal aumento do nível de pobreza, terá certamente impactos negativos no desempenho da economia, com perdas inclusive para frações dos setores hegemônicos.

Nos três temas analisados, as constatações são bastante negativas: no ideário pedagógico, pouco se avançou para além da crítica do tradicional formulada pelo escolanovismo que, muitas vezes assumida como posição de vanguarda, deixa de atentar para a importância vital da apropriação do conhecimento sistematizado, nas suas formas mais desenvolvidas, por parte da classe trabalhadora. Na questão do financiamento, igualmente, não há nada que indique uma reversão do padrão histórico de desvalorização da educação pública, não obstante a apregoada defesa da educação, tratada (somente nesse plano) como prioridade máxima. Todos estes elementos convergem para a inexistência de um sistema articulado de educação nacional com objetivos consistentes e emprego consequente dos meios necessários para atingi-los. Ao contrário, na política educacional prevalece a ambivalência e a descontinuidade.

Embora extrapolando os limites deste texto, não se pode evitar uma nota sobre os novos desafios colocados às lutas do campo educacional, ao lado da continuidade e aprofundamento de uma agenda ultraliberal, avanços do conservadorismo que marca o advento do governo Jair

A inexistência de um sistema articulado de educação nacional, conforme acima discutido, inviabiliza 0 estabelecimento de fins claros a serem atingidos, e dos meios indispensáveis a esses fins, predominando a descontinuidade das políticas educacionais. Bolsonaro (eleito para o mandato 2019-2022) em diversas vertentes: anticientificismo, fundamentalismo religioso, retrocesso em valores fundamentais relativos à tolerância e convivência na diversidade, e mesmo apologia de crimes hediondos, como a de grupos de extermínio e da tortura. E no campo educacional soma-se aos desafios já colocados pelos reformadores empresariais da edu- 
cação, os colocados pelos novos evangelizadores (FREITAS, 2019), cuja expressão mais contundente se dá no projeto escola sem partido.

À guisa de conclusão, vale destacar a existência de projetos antagônicos de educação em disputa, que se manifesta em contradições nas diversas esferas pedagógicas. De um lado um processo intenso de mercantilização, em que os recursos públicos (em um processo ora mais disfarçado, ora menos) acabam fluindo crescentemente para a esfera privada, que assume, segundo a lógica do lucro, não só atividades de concepção, mas até mesmo da própria realização, o que nos leva a colocar em questão a própria sobrevivência da escola pública, importante espaço formativo da juventude, crescentemente sob controle de grandes corporações educacionais. De outro lado, deve colocar-se a luta pelas bandeiras historicamente constituídas a favor da educação: um PNE que fortaleça a educação pública, com consequência no financiamento, com $10 \%$ do PIB já; valorização de fóruns democráticos que possam interferir na elaboração dos parâmetros da educação nacional; exigência de implementação da carreira, salário adequado e demais condições que dignifiquem a profissão docente, condição sine qua non para a efetivação da educação como direito social universalmente disponível à sociedade brasileira.

\section{Referências}

ALMEIDA, J. R. P. de. História da instrução pública no Brasil (1500-1889). São Paulo: EDUC; Brasília, DF: Instituto Nacional de Estudos e Pesquisas Educacionais Anísio Teixeira, 1989.

AMARAL, N. C. PEC 241/55: a "morte" do PNE (2014-2024) e o poder de diminuição dos recursos educacionais. Revista Brasileira de Política e Administração da Educação, v. 32, n. 3, p. 653-673, set./dez. 2016.

AMARAL, N. C. Com a PEC 241/55 (EC 95) haverá prioridade para cumprir as metas do PNE (2014-2024)? Revista Brasileira de Educação, Rio de janeiro, v. 22, n. 71, p. 1-25, out. 2017.

BRASIL. [Constituição (1988)]. Constituição Da República Federativa do Brasil de 1988. Brasília, DF: Presidência da República, [2019]. Disponível em: http://www.planalto.gov.br/ccivil_03/constituicao/ConstituicaoCompilado.htm. Acesso em: 19 jul. 2019.

BRASIL. [Constituição (1988)]. Emenda Constitucional $n^{\circ}$ 59, de 11 de novembro de 2009. Acrescenta $\S 3^{\circ}$ ao art. 76 do Ato das Disposições Constitucionais Transitórias para reduzir, anualmente, a partir do exercício de 2009, o percentual da Desvinculação das Receitas da União incidente sobre os recursos destinados à manutenção e desenvolvimento do ensino de que trata o art. 212 da Constituição Federal, dá nova redação aos incisos I e VII do art. 208, de forma a prever a obrigatoriedade do ensino de quatro a dezessete anos e ampliar a abrangência dos programas suplementares para todas as etapas da educação básica, e dá nova redação ao $\S 4^{\circ}$ do art. 211 e ao $\S 3^{\circ}$ do art. 212 e ao caput do art. 214, com a inserção neste dispositivo de inciso VI. Brasília, DF: Presidência da República, [2009a]. Disponível em: http://www.planalto.gov.br/ccivil_03/constituicao/Emendas/Emc/emc59.htm. Acesso em: 19 jul. 2019.

BRASIL. [Constituição (1988)]. Emenda Constitucional n 27, de 21 de março de 2000. Acrescenta o art. 76 ao ato das Disposições Constitucionais Transitórias, instituindo a desvinculação de arrecadação de impostos e contribuições sociais da União. Brasília, DF: Presidência da República, [2000]. Disponível em: http://www.planalto.gov.br/ccivil_03/constituicao/Emendas/Emc/emc27.htm. Acesso em: 19 jul. 2019.

BRASIL. [Constituição (1988)]. Emenda Constitucional nº 95, de 15 de dezembro de 2016.

Altera o Ato das Disposições Constitucionais Transitórias, para instituir o Novo Regime Fiscal, e dá outras providências. Brasília, DF: Presidência da República, [2016]. Disponível em: http://www.planalto.gov.br/ccivil_03/constituicao/Emendas/Emc/emc95.htm. Acesso em: 19 jul. 2019.

BRASIL. Lei n ${ }^{\circ}$ 10.172, de 9 de janeiro de 2001. Aprova o Plano Nacional de Educação e dá outras providências. Brasília, DF, [2009b]. Disponível em: http://http://www.planalto.gov.br/ccivil_03/leis/leis_2001/110172.htm. Acesso em: 30 jan. 2019.

BRASIL. Lei $n^{\circ} 13.005$, de 25 de junho de 2014. Aprova o Plano Nacional de Educação - PNE e dá outras providências. Brasília, DF: Presidência da República, [2014]. Disponível em: http://www.planalto.gov.br/ccivil_03/_ato2011-2014/2014/lei/113005.htm. Acesso em: 19 jul. 2019.

DAVIES, N. O financiamento da educação estatal no Brasil: velhos e novos desafios. Revista Brasileira de Política e Administração da Educação, v. 16, n. 2, p. 159-176, jul./dez. 2000.

DAVIES, N. FUNDEB: a redenção da educação básica? Educação e Sociedade, Campinas, v. 27, n. 96, p. 753-774, out. 2006.

DUARTE, N. O debate contemporâneo das teorias pedagógicas. In: MARTINS, L.; DUARTE, N. (org.). Formação de professores: limites contemporâneos e alternativas necessárias. São Paulo: Ed. UNESP: Cultura acadêmica, 2010. p. 33-49.

DUARTE, N. A individualidade para si. 3. ed. Campinas: Autores Associados, 2013.

ENGELS, F. Anti-Dühring: a revolução da ciência segundo o senhor Eugen Dühring. São Paulo: Boitempo, 2015.

FREITAS, L. C. Os "novos evangelizadores". Avaliação educacional - Blog do Freitas. [S. 1.], 3 jan. 2019. Disponível em: https:// avaliacaoeducacional.com/2019/01/03/os-novos-evangelizadores. Acesso em: 31 jan. 2019.

GRAMSCI, A. Os intelectuais e a organização da cultura. 9. ed. Rio de Janeiro: Civilização Brasileira, 1995.

HADDAD, S. (org.) et al. Banco Mundial, OMC e FMI: o impacto nas políticas educacionais. São Paulo: Cortez, 2008. 
HARVEY, D. A loucura da razão econômica: Marx e o capital no século XXI. São Paulo: Boitempo, 2018.

INSTITUTO NACIONAL DE ESTUDOS E PESQUISAS EDUCACIONAIS ANÍSIO TEIXEIRA. Mapa do Analfabetismo no Brasil. Brasília, DF: Ministério da Educação, [200-].

JACOMINI , M. A., PENNA, M. G. de O. Carreira docente e valorização do magistério: condições de trabalho e desenvolvimento profissional. Pro-posições, Campinas v. 27, n. 2, p. 177-202, maio/ago. 2016.

LIMA, K. R. de S. A educação superior no plano nacional de educação 2011-2020. Perspectiva, Florianópolis, v. 30, n. 2, p. 625-656, maio/ago. 2012 .

LIMA, K. R. de S. Plano Nacional de Educação 2014-2024: nova fase do privatismo e da certificação em larga escala. Universidade e Sociedade. Brasília, DF, ano 27, n. 55, p. 32-43, fev. 2015.

PINTO, J. M. de R. O financiamento da educação na Constituição Federal de 1988: 30 anos de mobilização social. Educação \& Sociedade, Campinas, v. 39, n. 145, p. 846-869, out./dez. 2018.

SAVIANI, D. Pedagogia histórico-crítica: primeiras aproximações. 9. ed. Campinas: Autores Associados, 2005.

SAVIANI, D. Escola e Democracia. Campinas: Autores Associados, 2008a.

SAVIANI, D. Desafios da construção de um sistema nacional articulado de educação. Trabalho, Educação e Saúde, Rio de Janeiro, v. 6 , n. 2, p. 213-231, jul./out. 2008b.

SAVIANI, D. História das ideias pedagógicas no Brasil. 4. ed. Campinas: Autores Associados, 2013.

SAVIANI, D. Sistema Nacional de Educação e Plano Nacional de Educação: significado, controvérsias e perspectivas. 2. ed. Campinas: Autores Associados, 2017.

\section{Notas}

1 Este número de mais de 16 milhões de pessoas corresponde ao critério de aferição do analfabetismo levando-se em consideração habilidades mínimas de leitura e escrita. Caso se considere um critério mais abrangente, de acordo com a noção de analfabeto funcional (referida aos indivíduos com capacidade muito restrita de interpretação de textos), o número de analfabetos no país “[...] salta para mais de 30 milhões de brasileiros, considerando a população de 15 anos ou mais". (INSTITUTO NACIONAL DE ESTUDOS E PESQUISAS EDUCACIONAIS ANÍSIO TEIXEIRA, [200-], p. 7).

2 Saviani (2008b) cita, nesse sentido, a inconsistência entre a determinação da Carta Magna de 1988 de conferir exclusividade aos âmbitos, federal, e estaduais na definição de normas legais, e ainda assim, fazer referência explícita a supostos sistemas municipais de ensino.

3 Pode-se citar como exemplo a Contribuição para o Financiamento da Seguridade Social (COFINS), e a Contribuição Provisória sobre Movimentação Financeira (CPMF), que vigorou de 1997 a 2007. Pode-se citar como exemplo a Contribuição para o Financiamento da Seguridade Social (COFINS), e a Contribuição Provisória sobre Movimentação Financeira (CPMF), que vigorou de 1997 a 2007.

4 Esse espúrio mecanismo foi criado em 1994, como Fundo Social de Emergência, que seria substituído em 1996 pelo Fundo de Estabilização Fiscal, prorrogado até 1999. A partir de 2000, por meio da EC 27/2000 (BRASIL, [200]), surge a Desvinculação das Receitas da União (DRU), continuando assim o mecanismo, com pequenas variantes, de desvinculação de $20 \%$ da receita de impostos e contribuições da União. Vale citar ainda o puro descumprimento do preceito legal. Davies (2000) refere-se a vários casos de descumprimento do mínimo legalmente instituído para as despesas educacionais, como o caso do Estado de São Paulo, onde foram aplicados no setor R \$ 5,2 bilhões a menos do que o exigido legalmente, somente no período de 1995 a 1998.

\section{Benedito de Jesus Pinheiro Ferreira}

ferreira@ufpa.br

Doutorado em Engenharia de Sistemas e Computação pela COPPE da Universidade Federal do Rio de Janeiro (UFRJ)

Professor do Programa de Pós-graduação em Educação da Universidade Federal do Pará (UFPA)

\section{UFPA}

Rua Augusto Corrêa, 01 - Guamá

Belém - Pará - Brasil

CEP: $66.075-110$

\section{Agradecimentos}

A Joana Valente Santana, companheira de vida e de luta, inclusive nessa indispensável modalidade de luta que é o estudo orientado pela teoria social marxiana, agradeço a atenta leitura e as ricas sugestões.

\section{Agência financiadora}

Não se aplica. 
Contribuições das autoras

Não se aplica.

\section{Conflito de interesses}

Não há conflito de interesses.

Aprovação por Comitê de Ética e consentimento para parti-

cipação

Não se aplica.

Consentimento para publicação

Não se aplica. 